\title{
PENINGKATAN KUALITAS PELAYANAN DENGAN METODE SERVQUAL DAN TRIZ DI PT. XYZ
}

\author{
Nofi Erni' ${ }^{1)}$, Iphov Kumala Sriwana ${ }^{1)}$ dan Wira Tri Yolanda ${ }^{2)}$ \\ ${ }^{1)}$ Program Studi Teknik Industri, Universitas Esa Unggul \\ ${ }^{2)}$ Program Studi Teknik Industri, Universitas Tarumanagara \\ e-mail: wiratriyolanda@gmailcom
}

\begin{abstract}
ABSTRAK
Persaingan yang semakin ketat dan sulit diprediksikan menuntut setiap perusahaan untuk meningkatkan kualitas produk yang dihasilkan. Penelitian ini dilakukan di PT. XYZ cabang Pondok Indah dan Pondok Pinang, salah satu perusahaan di bidang jasa pengiriman barang dan logistik. Pada industri ini, pelayanan yang menjadi produk inti yang harus dikelola dengan baik untuk meningkatkan kepuasan pelanggan. Metode yang digunakan pada penelitian ini dengan menggunakan metode SERVQUAL untuk menganalisa permasalahan yang terjadi yang berhubungan dengan kualitas layanan, dan metode TRIZ untuk memecahkan permasalahannya. Hasil penelitian menunjukkan perbaikan yang diusulkan pada 5 atribut yang memiliki nilai kesenjangan terbesar antara persepsi dan harapan pelanggan. Berdasarkan hasil analisis dengan metode TRIZ, solusi usulan untuk perbaikan kualitas pelayanan yaitu meletakkan nomor antrian pada ketinggian $1325 \mathrm{~mm}$ dan di depan pintu masuk, memisahkan dan mengklasifikasikan barang-barang yang akan dikirim menjadi beberapa kategori, merubah kertas hvs menjadi kertas dengan kualitas dan ketebalan yang baik dan menggunakan warna cerah seperti warna biru sebagai background pada papan informasi, memberikan pelatihan secara berkala kepada para staf, serta memberikan reward kepada staff yang memberikan pelayanan terbaik dan punishment pada karyawan yang memberikan pelayanan buruk.
\end{abstract}

Kata kunci: Kualitas Pelayanan, Kepuasan Pelanggan, SERVQUAL, TRIZ.

ABSTRACT

Competition is becoming increasingly fierce and difficult to predict requires every company to improve which quality of the resulting product. The research was conducted in PT. XYZ branch Pondok Indah and Pondok Pinang, one of the companies in the field of freight forwarder and logistics services. In this industry, services into the core product must be managed properly to increase customer satisfaction. The method used in this research is SERVQUAL method to analyze problems related to quality of service, and TRIZ method for solving the problems. The result of this research shows prpopsed improvements on the 5 attributes with the greatest value gap between perseption and expectation of costumers. Based on analysis result with TRIZ method, give an idea for the repair of service quality that is put the queue numbers at a height of $1325 \mathrm{~mm}$ in front of the enrance, separating and classifying the items to be sent into several categories, change the HVS paper into the paper with good quality and thickness and using bright color such as blue as the background on information board, provide regular training to staff and provide rewards to staff who provide the best service and the punishment to staff who provide bad service.

Keywords: Quality of service, customer satisfaction, SERVQUAL, TRIZ .

\section{PENDAHULUAN}

Globalisasi membawa dampak yang sangat besar bagi perkembangan dunia bisnis di seluruh dunia. Pasar terbuka luas dan peluang menjadi semakin lebar. Namun sebaliknya, persaingan menjadi semakin ketat dan sulit diprediksi. Kondisi ini menuntut setiap perusahaan untuk meningkatkan kualitas produk yang dihasilkan demi tercapainya kepuasan pelanggan.

PT. XYZ merupakan perusahaan yang bergerak di bidang jasa pengiriman barang dan logistik. Perusahaan ini dalam perjalanan usahanya terdapat beberapa permasalahan yang terjadi, seperti keterlambatan dan kerusakan dalam pengiriman. Hal ini dapat menyebabkan penurunan kepuasan pelanggannya.

Batasan masalah dalam penilitian ini yaitu lokasi penelitian dan pengambilan data di PT. XYZ cabang Pondok Indah dan Pondok Pinang yang dilakukan dari bulan SeptemberNovember 2013 dan tinjauan kualitas pelayanan yang diamati hanya pada aspek pelayanan pengiriman saja. Tujuan penelitian ini adalah 
mengidentifikasi faktor-faktor yang mempengaruhi kepuasan pelanggan dan memberikan usulan untuk meningkatkan kualitas pelayanan di PT. XYZ.

\section{TINJAUAN PUSTAKA}

Kualitas jasa didefinisikan sebagai keseluruhan gabungan karakteristik produk dan jasa yang dihasilkan dari pemasaran, rekayasa, produksi, dan pemeliharaan yang membuat produk dan jasa tersebut dapat digunakan memenuhi harapan pelanggan atau konsumen. Jasa yang berkualitas harus bisa memenuhi atau melebihi ekspektasi pelanggan yang dapat dijelaskan melalui hal-hal yang sering disebut dimensi kualitas dimana terdapat delapan dimensi kualitas [1].

Pelanggan adalah semua orang yang menuntut perusahaan untuk memenuhi suatu standar kualitas tertentu, karena itu akan memberikan pengaruh pada perfomansi perusahaan [2]. Kepuasan pelanggan adalah perasaan senang atau kecewa seseorang yang muncul setelah membandingkan antara persepsi terhadap kinerja (performance) suatu produk dan harapan-harapannya. Jika kinerja melebihi harapan, pelanggan amat puas atau senang [3]. Faktor-faktor yang mempengaruhi persepsi dan ekspektasi pelanggan adalah Kebutuhan dan keinginan yang berkaitan dengan hal-hal yang dirasakan pelanggan, pengalaman masa lalu, komunikasi melalui iklan dan pengalaman dari teman-teman [2].

Pengujian validitas data digunakan untuk mengukur sah atau valid tidaknya suatu kuesioner. Suatu kuesioner dianggap valid jika pertanyaan pada kuesioner mampu mengungkapkan sesuatu yang diukur oleh kuesioner tersebut. Reliabilitas adalah alat untuk mengukur suatu kuesioner yang merupakan indikator dari variabel atau konstruk. Suatu kuesioner dapat dikatakan reliable atau handal jika jawaban seseorang terhadap pertanyaan adalah konsisten atau stabil [4].

Metode Service Quality (SERVQUAL) merupakan metode pengukuran kualitas pelayanan yang dapat mengetahui aspek kualitas pelayanan yang perlu mendapat perbaikan. Metode ini mampu menterjemahkan ekspektasi pelanggan yang masih belum terakomodir sepenuhnya oleh pihak perusahaan, sehingga memerlukan adanya peningkatan kualitas layanan yang diberikan [5]. Terdapat lima dimensi SERVQUAL yaitu tangible, reliability, responsiveness, assurance dan emphaty [6]. Penyebab ketidaksesuaian harapan dengan persepsi para pelanggan terhadap suatu pelayanan yaitu karena lima macam gap [8]. Importance Performance Analysis (IPA) digunakan untuk memperoleh faktor-faktor yang berpengaruh pada hasil yang diperoleh dari dimensi SERVQUAL. Hasil dari dimensi SERVQUAL disampaikan dalam bentuk diagram kartesius yang memiliki 4 kuadran [1].

TRIZ singkatan dari bahasa rusia Teoriya Resheniya Izobreatatelskikh Zadatch (Teori Inovatif pemecahan masalah) yaitu metode kreatif yang digambarkan sebagai suatu proses pemecahan masalah terstruktur yang menunjukkan bagaimana teknologi memecahkan hambatan yang muncul. Pendekatan yang lebih baik dalam pemecahan masalah yang mengandalkan pada teknologi bukan pada pendekatan psikologi ini pertama kali dikembangkan oleh Genrich S.Altshuller, yang lahir di bekas Uni Soviet pada tahun 1926. Menemukan prinsip yang perlu diubah kemudian cari prinsip dari efek yang tidak diinginkan. Untuk mewakili kontradiksi teknis ini, TRIZ telah memilih 39 parameter sistem yang menyebabkan konflik. Untuk mencari solusi yang analog dan beradaptasi dengan solusi peneliti, terdapat 40 prisip TRIZ yang merupakan petunjuk untuk membantu seorang peneliti menemukan solusi dari masalah yang ada [7].

\section{METODE PENELITIAN}

Langkah-langkah metodologi penelitian yang dilakukan dalam penelitian ini dimulai dari merumuskan masalah, menentukan tujuan penelitian, menentukan landasan teori, pengumpulan data pendahuluan untuk mengetahui atribut yang SERVQUAL, penyebaran kuesioner awal yang kemudian didapat atribut-atribut yang akan digunakan dalam kuesioner SERVQUAL. Menentukan jumlah sampel untuk penyebaran kuesioner dan 
kemudian kuesioner disebarkan dan dikumpulkan.

Kuesioner yang sudah dikumpulkan selanjutnya dilakukan uji validitas dan reabilitas untuk mengetahui apakah data kuesioner yang sudah disebar dapat diandalkan dan dijadikan alat ukur untuk memperoleh informasi dalam penelitian ini. setelah data dianggap valid dan reliabel selanjutnya dilakukan perhitungan gap dan importance performance analisis dalam bentuk diagram kartesius. Dari perhitungan nilai gap dan IPA didapat atribut yang memiliki kualitas terendah yang untuk selanjutnya atribut tersebut digunakan untuk pengembangan dan pemecahan masalah dengan metode TRIZ. Diagram alir penelitian dapat dilihat pada Gambar 1.

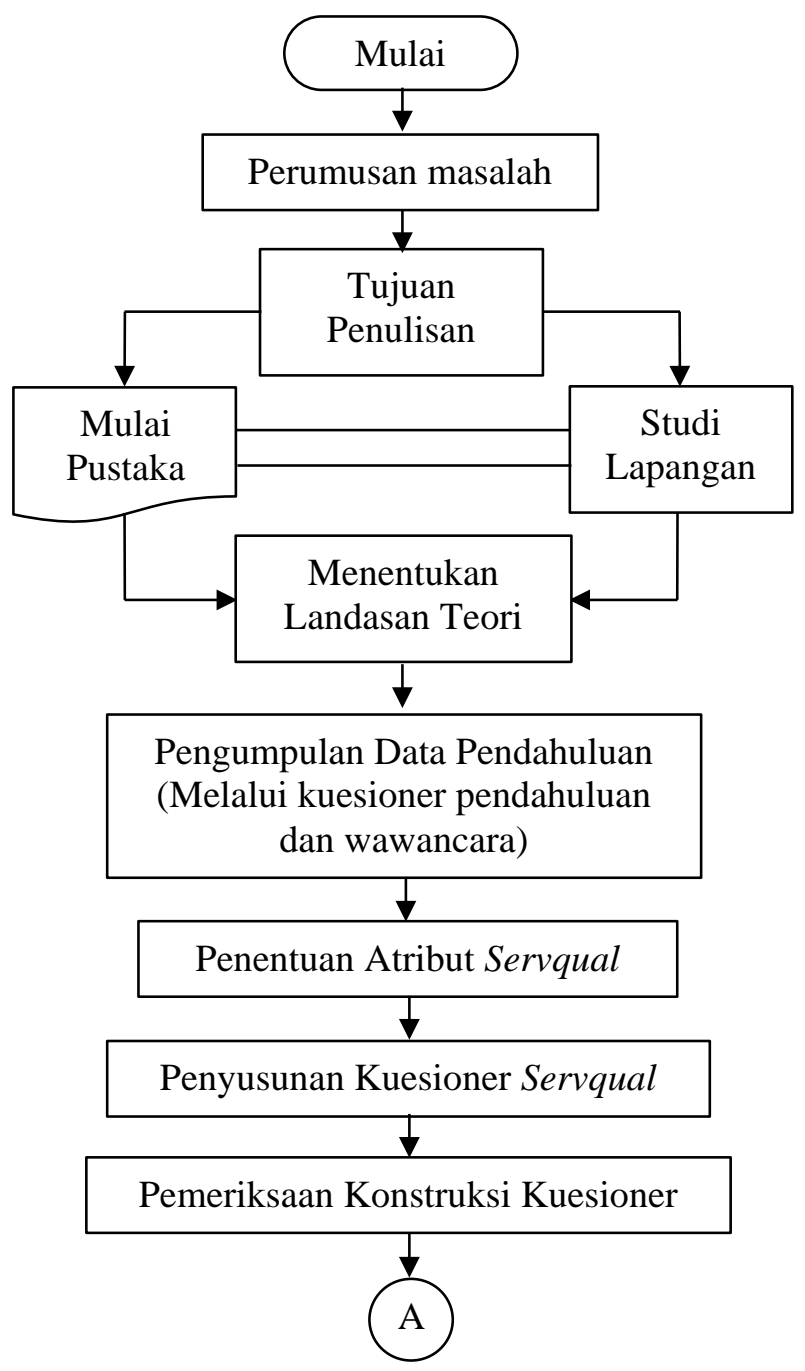

Gambar 1. Diagram Alir Penelitian
Lanjutan Gambar 1. Diagram Alir Penelitian

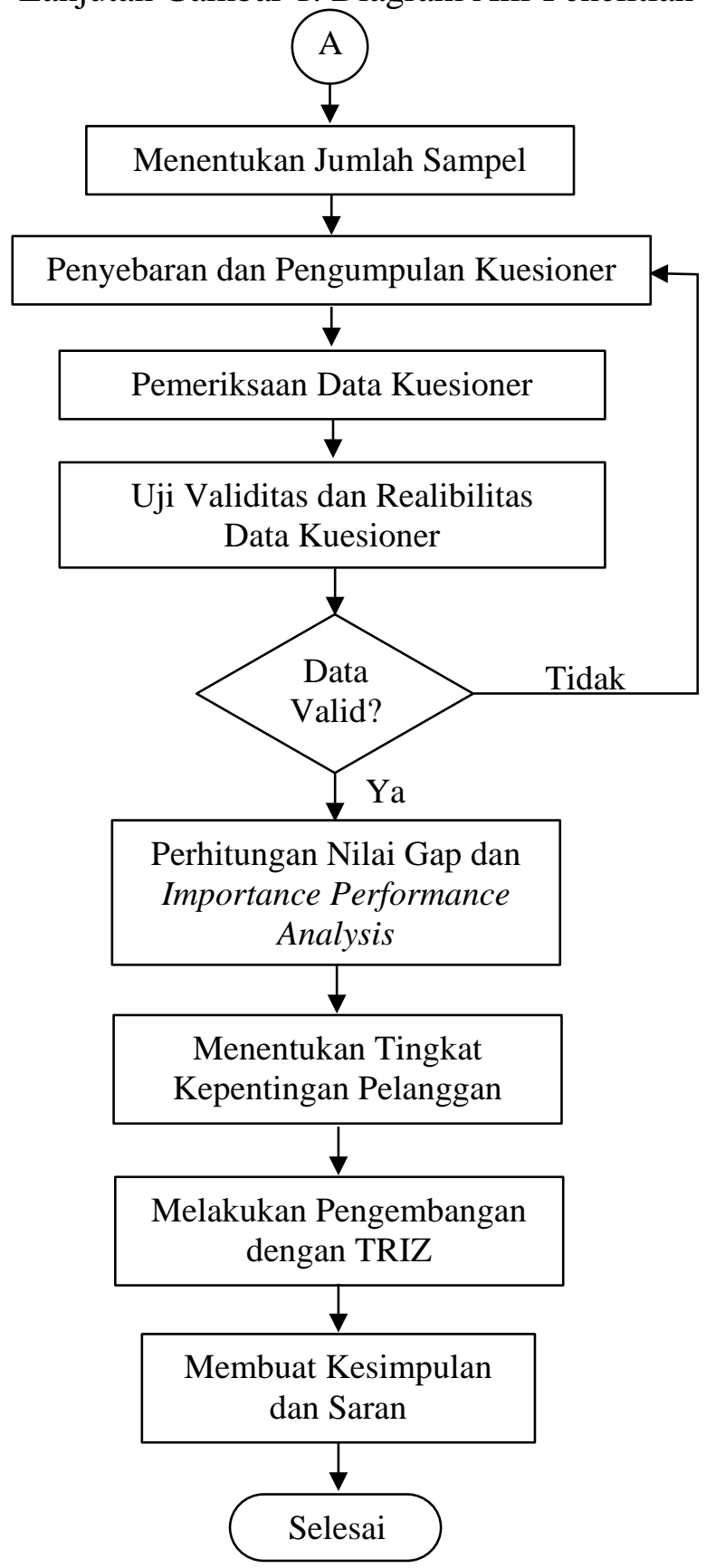

HASIL DAN PEMBAHASAN

\section{Kuesioner SERVQUAL}

Setelah penyebaran pra kuesioner kepada 30 responden dan sudah dianggap cukup, selanjutnya pengelompokkan atribut ke dalam dimensi SERVQUAL. Atribut-atribut tersebut digunakan sebagai alat ukur dalam kuesioner untuk mengetahui indeks kepuasan konsumen dan besarnya gap antara persepsi dan harapan konsumen. Atribut-atribut yang diukur dalam kuesioner SERVQUAL dapat dilihat pada Tabel 1. 
Tabel 1. Atribut Kuesioner SERVQUAL

\begin{tabular}{ccl}
\hline No & Atribut & \\
\hline 1 & T1 & Kebersihan dan kerapihan ruang pendaftaran \\
2 & T2 & Kelengkapan fasilitas ruang tunggu \\
3 & T3 & Peralatan untuk membungkus barang yang akan dikirim memadai \\
4 & T4 & Paket layanan untuk setiap spesifikasi produk \\
5 & T5 & Tempat parkir kendaraan \\
6 & T6 & Letak yang strategis \\
7 & T7 & Letak papan informasi dan isinya \\
8 & T8 & Nomor antrian \\
9 & E1 & Mengingatkan untuk membawa dan menyimpan bukti pengiriman \\
10 & E2 & Merekomendasikan jenis packaging yang sebaiknya digunakan \\
11 & E3 & Menangani keluhan pelanggan dengan baik \\
12 & E4 & Menjaga catatan transaksi yang akurat \\
13 & E5 & Kesediaan staf untuk membantu pelanggan \\
14 & R1 & Kecepatan dalam melayani pelanggan \\
15 & R2 & Ketepatan waktu barang sampai di tempat tujuan \\
16 & R3 & Produk yang dikirimkan bebas dari kerusakan \\
17 & R4 & Penjelasan yang baik mengenai biaya dan estimasi waktu \\
18 & R5 & Mampu menggunakan Internet \\
19 & R6 & Kesabaran staf dalam melayani pelanggan \\
20 & RV1 & Kemudahan dalam proses pendaftaran pengiriman barang \\
21 & RV2 & Memecahkan masalah secepat mungkin \\
22 & RV3 & Pengecekan barang yang akan dikirim bersama pelanggan \\
23 & RV4 & Menginformasikan mengenai waktu pengiriman, sebelum pendaftaran dianggap selesai \\
24 & RV5 & Nomor resi untuk pelacakan barang pada bukti pengiriman \\
25 & A1 & Staff sopan dan ramah \\
26 & A2 & Garansi dari produk yang dikirim berdasarkan packaging yang digunakan \\
27 & A3 & Tanggung jawab perusahaan atas kehilangan barang yang dikirim \\
28 & A4 & Harga sesuai dengan layanan \\
\hline & &
\end{tabular}

\section{Penentuan Sampel}

Untuk menentukan berapa banyak sampel yang perlu diambil untuk melakukan penelitian, penulis menggunakan rumus slovin [8] yaitu:

$$
\begin{aligned}
n & =\frac{N}{N \cdot d^{2}+1}=\frac{4920}{4920 x(0,1)^{2}+1} \\
& =\frac{4920}{4920 x(0,1)^{2}+1} \\
& =\frac{4920}{50,2}=98=100
\end{aligned}
$$

Penyebaran kuesioner dilakukan di dua cabang, maka pengambilan sampel dilakukan dengan teknik propotional sampling [9]. Penetapan jumlah sampel masing-masing cabang ditetapkan berdasarkan perbandingan jumlah yang dilayani PT. XYZ cabang Pondok Indah dan Pondok Pinang. Dari hasil persentase diperoleh 60\% cabang Pondok Indah dan 40\% cabang Pondok Pinang, dengan demikian jumlah sampel yang dibutuhkan pada penelitian ini yaitu 60 pada cabang Pondok Indah dan 40 pada cabang pondok Pinang.

\section{Uji Validitas}

Setelah kuesioner disebarkan dan dikumpulkan, selanjutnya dilakukan pengujian validitas data. Pengujian ini dilakukan dengan mengkorelasikan butir pernyataan dengan nilai total dari 100 responden. Langkah yang dilakukan dalam uji validitas untuk setiap butir pernyataan pada kuesioner tersebut adalah:

1. Menentukan hipotesis

$\mathrm{H}_{0}$ : Terdapat korelasi antara setiap butir pernyataan dengan nilai penilaian total.

$\mathrm{H}_{1}$ : Tidak terdapat korelasi antara setiap butir pernyataan dengan nilai penilaian total.

2. Menentukan nilai $r$ tabel

Nilai $r$ tabel didapat dari tabel statistika untuk uji 2 arah dengan taraf signifikan $(\alpha)$ $5 \%$ dengan jumlah sampel 100 maka $n=100$, $\mathrm{DF}=98$ maka $r$ tabel $=0,196$ 
3. Mencari r hitung

Mencari $r$ hitung menggunakan teknik korelasi product moment [8] sebagai berikut:

$\mathrm{r}_{\text {hitung }}=\frac{N\left(\sum X Y\right)-\left(\sum X \sum Y\right)}{\sqrt{\left\{\left(N \sum X^{2}\right)-\left(\sum X\right)^{2}\right\}\left\{\left(N \sum Y^{2}\right)-\left(\sum Y\right)^{2}\right\}}}$

Contoh perhitungan $r$ hitung untuk atribut T1 yaitu:

$$
\begin{aligned}
\mathrm{T}_{1} & =\frac{100(39344)-[(374)(10369)]}{\sqrt{\left.(374]^{2}\right]\left[100(1089089)-(10369)^{2}\right]}} \\
& =\frac{3934400-3878006}{\sqrt{(6124)(1392739)}}=\frac{56394}{92353,31}=0,6106
\end{aligned}
$$

4. Mengambil keputusan

Terima $\mathrm{H}_{0}$ jika $\mathrm{r}$ hitung $>\mathrm{r}$ tabel, dan sebaliknya.

5. Keputusan

Jadi dapat disimpulkan terima $\mathrm{H}_{0}$ yang berarti terdapat korelasi antara setiap butir pernyataan dengan nilai penilaian total sehingga dianggap valid.

\section{Uji Reliabilitas}

Uji Reliabilitas ini menggunakan software SPSS versi 17 dan teknik yang digunakan adalah alpha cronbach terhadap data yang diperoleh dari kuesioner. Perhitungan analisa reliabilitas dilakukan dengan menggunakan program SPSS, yang kemudian akan diperoleh koefisien alpha $(\alpha)$ cronbach. Pernyataan dapat dikatakan reliabel atau handal jika nilai alpha melebihi 0,6. Dari hasil tersebut didapat nilai alpha sebagai berikut:

1. Nilai Alpha untuk pernyataan persepsi = 0,931

2. Nilai Alpha untuk pernyataan harapan = 0,919

Dari kedua nilai tersebut diketahui bahwa untuk pernyataan persepsi dan harapan mempunyai nilai lebih dari 0,6 . Sehingga dapat disimpulkan bahwa kuesioner sudah reliable dan dapat digunakan untuk penelitian ini.

\section{Hasil Perhitungan Nilai Gap Dimensi SERVQUAL}

Nilai gap didapatkan dari hasil perhitungan nilai rata-rata persepsi dikurangi nilai rata-rata harapan responden pada setiap atribut. Hasil perhitungan nilai gap antara persepsi dan harapan dapat dilihat pada Tabel 2.

Diagram hasil nilai gap antara persepsi dan harapan pelanggan (nilai gap dalam minus) dapat dilihat pada Gambar 2.

Tabel 2. Nilai Gap Antara Persepsi dan Harapan

\begin{tabular}{ccccc}
\hline & \multicolumn{3}{c}{ Rata-rata } \\
No & Atribut & $\begin{array}{c}\text { Rata-rata } \\
\text { harapan } \\
(\mathrm{x})\end{array}$ & $\begin{array}{c}\text { Nilai gap } \\
(\mathrm{x}-\mathrm{y})\end{array}$ \\
\hline 1 & T1 & 3,74 & 4,27 & $-0,53$ \\
2 & T2 & 3,76 & 4,33 & $-0,57$ \\
3 & T3 & 3,89 & 4,42 & $-0,53$ \\
4 & T4 & 3,82 & 4,21 & $-0,39$ \\
5 & T5 & 3,55 & 4,31 & $-0,76$ \\
6 & T6 & 3,61 & 4,38 & $-0,77$ \\
7 & T7 & 3,27 & 4,33 & $-1,06$ \\
8 & T8 & 2,78 & 4,24 & $-1,46$ \\
9 & E1 & 3,63 & 4,27 & $-0,64$ \\
10 & E2 & 3,85 & 4,20 & $-0,35$ \\
11 & E3 & 3,61 & 4,58 & $-0,97$ \\
12 & E4 & 3,86 & 4,34 & $-0,48$ \\
13 & E5 & 3,81 & 4,47 & $-0,66$ \\
14 & R1 & 3,57 & 4,60 & $-1,03$ \\
15 & R2 & 3,85 & 4,63 & $-0,78$ \\
16 & R3 & 3,55 & 4,66 & $-1,11$ \\
17 & R4 & 3,79 & 4,31 & $-0,52$ \\
18 & R5 & 3,70 & 4,02 & $-0,32$ \\
19 & R6 & 3,83 & 4,51 & $-0,68$ \\
20 & RV1 & 3,86 & 4,27 & $-0,41$ \\
21 & RV2 & 3,74 & 4,37 & $-0,63$ \\
22 & RV3 & 3,80 & 4,31 & $-0,51$ \\
23 & RV4 & 3,71 & 4,41 & -070 \\
24 & RV5 & 4,15 & 4,76 & $-0,61$ \\
25 & A1 & 3,94 & 4,47 & $-0,53$ \\
26 & A2 & 3,58 & 4,46 & $-0,88$ \\
27 & A3 & 3,64 & 4,70 & $-1,06$ \\
28 & A4 & 3,80 & 4,37 & $-0,57$ \\
\hline & & & &
\end{tabular}

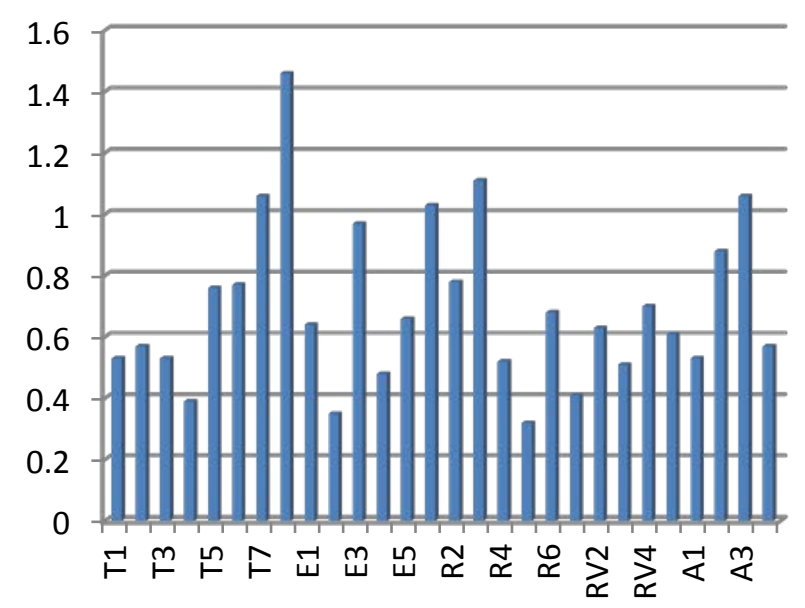

Gambar 2. Diagram Nilai Gap Antara Persepsi dan Harapan 
Importance Performance Analysis

Importance Performance

Analysis digunakan untuk mengetahui faktor-faktor yang berpengaruh terhadap hasil yang diperoleh dari dimensi SERVQUAL. Hasil Importance Performance Analysis berupa diagram kartesius untuk mengetahui letak kuadran setiap atribut. Diagram hasil Importance Performance Analysis dapat dilihat pada Gambar 3.

\section{Nilai Persepsi Pelanggan Terhadap Kinerja Pelayanan}

Untuk mendapatkan nilai persepsi pelanggan untuk setiap atribut pelayanan adalah dengan menghitung skor total masing-masing atribut pelayanan dibagi jumlah responden. Contoh perhitungan untuk mendapatkan nilai persepsi untuk atribut T1 adalah:

$\mathrm{P}_{1}=0 ; \mathrm{P}_{2}=5 ; \mathrm{P}_{3}=32 ; \mathrm{P}_{4}=47 ; \mathrm{P}_{5}=16$

$$
\begin{aligned}
\mathrm{TP}_{\mathrm{T} 1} & =\frac{(0 \times 1)+(5 \times 2)+(32 \times 3)+(47 \times 4)+(16 \times 5)}{100} \\
& =\frac{374}{100}=3,74
\end{aligned}
$$

Untuk diagram nilai persepsi setiap atribut pelayanan dapat dilihat pada Gambar 3.

\section{Nilai Harapan Pelanggan Terhadap Kualitas Pelayanan}

Nilai harapan yaitu nilai untuk mengukur penting atau tidaknya suatu atribut. Untuk mendapatkan nilai harapan pelanggan untuk setiap atribut pelayanan sama seperti pada perhitungan nilai persepsi yaitu dengan menghitung skor total masing-masing atribut pelayanan dibagi jumlah responden. Contoh perhitungan untuk mendapatkan nilai harapan untuk atribut $\mathrm{T} 1$ adalah:

$\mathrm{H}_{1}=0 ; \mathrm{H}_{2}=0 ; \mathrm{H}_{3}=8 ; \mathrm{H}_{4}=57 ; \mathrm{H}_{5}=35$

$$
\begin{aligned}
\mathrm{TH}_{\mathrm{T} 1} & =\frac{(0 \times 1)+(0 \times 2)+(8 \times 3)+(57 \times 4)+(35 \times 5)}{100} \\
& =\frac{427}{100}=4,27
\end{aligned}
$$

Untuk diagram nilai harapan setiap atribut pelayanan dapat dilihat pada Gambar 3.

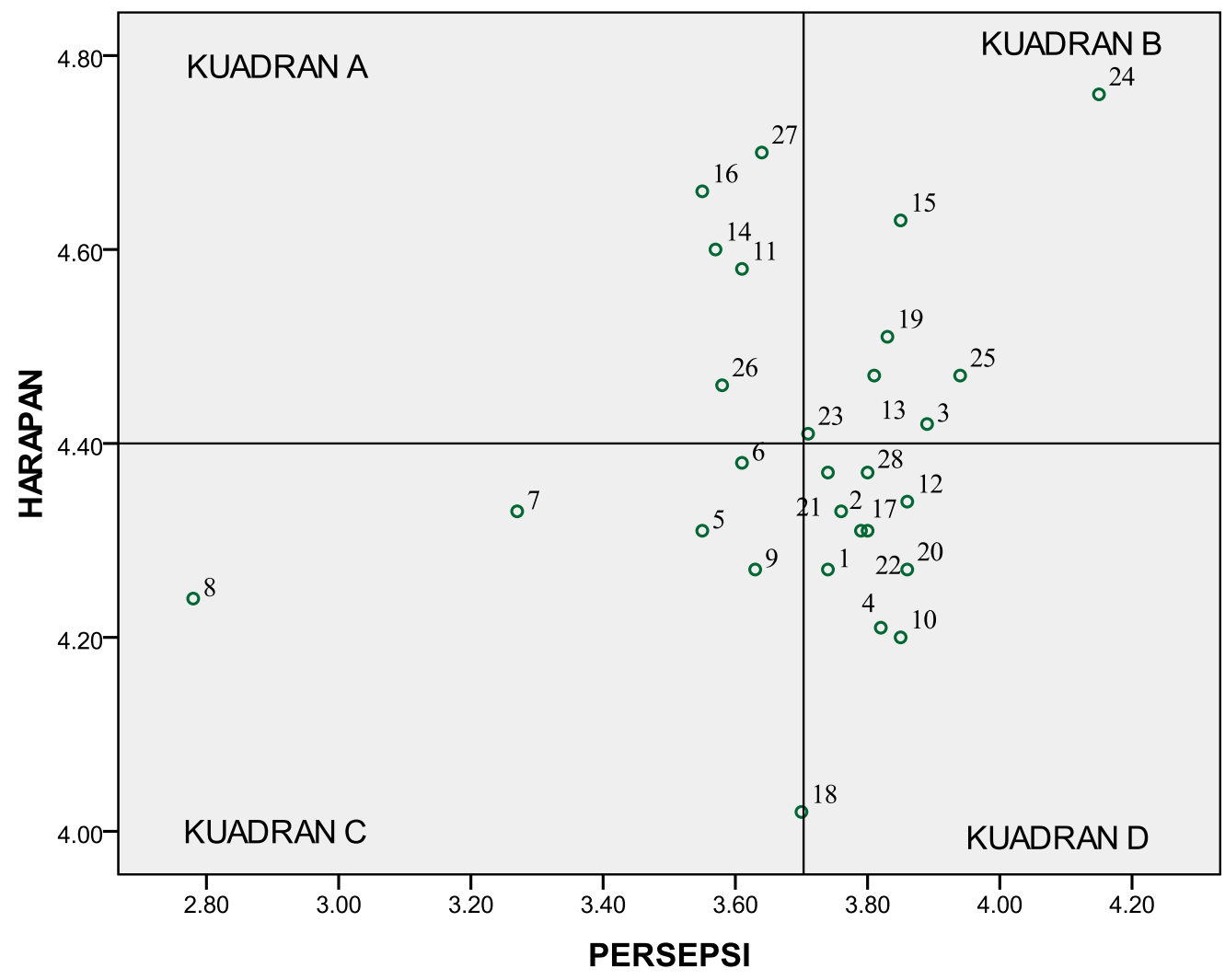

Gambar 3. Diagram hasil Importance Performance Analysis 

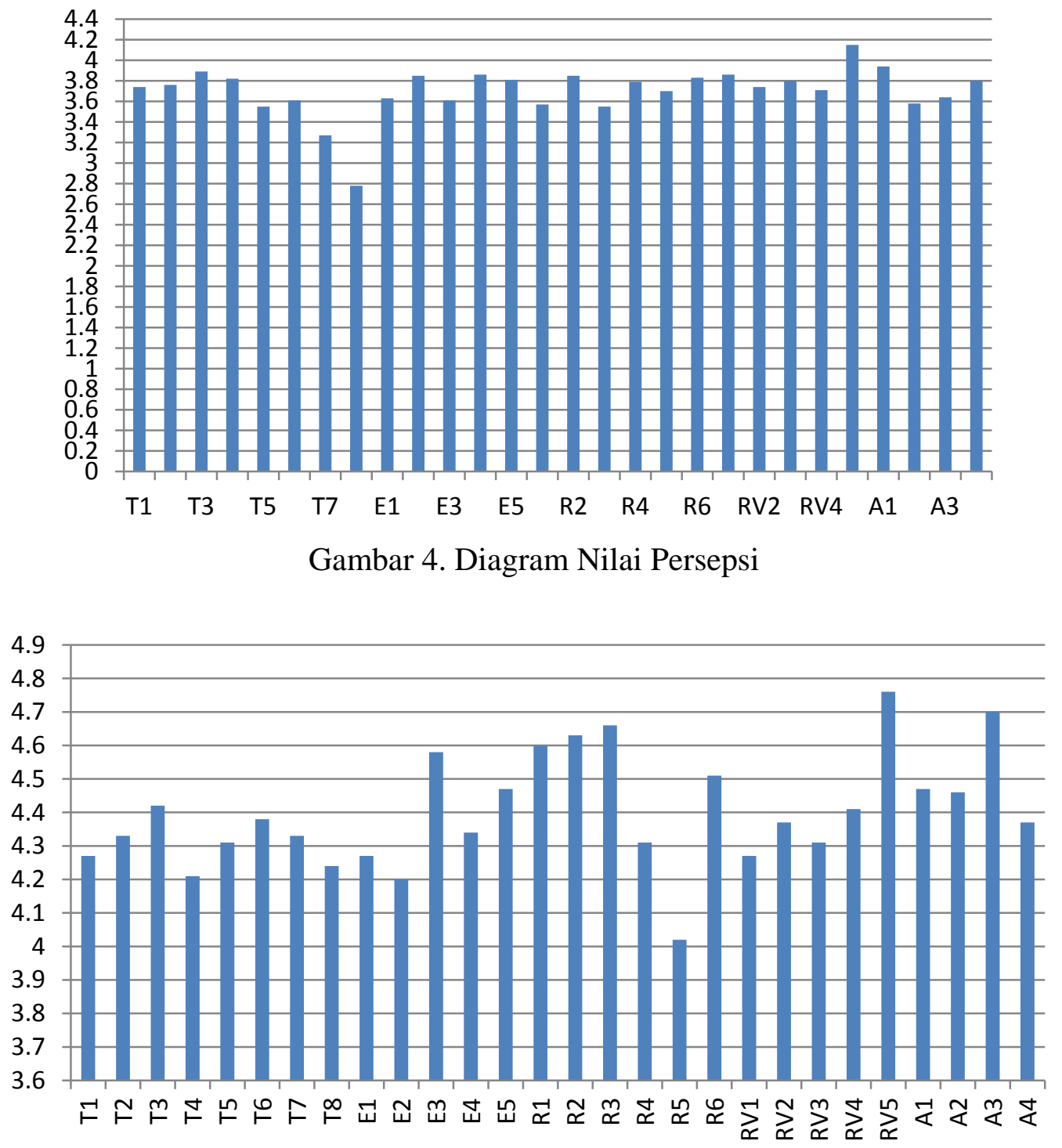

Gambar 4. Diagram Nilai Harapan

\section{Penentuan Prioritas Perbaikan}

Perbaikan dilakukan pada atribut yang memiliki nilai gap terbesar dan memungkinkan untuk pengembangan dalam memecahkan masalahnya dapat dilakukan, sehingga atribut yang akan dilakukan perbaikan terdiri dari 5 atribut yaitu:

T8 : Nomor antrian

R3 : Produk yang dikirimkan bebas dari kerusakan

T7 : Papan informasi dan isinya

R1 : Kecepatan dalam melayani pelanggan

E3 : Menangani keluhan pelanggan dengan baik

\section{Usulan Perbaikan Atribut dengan TRIZ}

1. Nomor Antrian
Dari keempat prinsip yang terdeteksi, hanya prinsip no. 32 dan 23 yang dipilih sebagai acuan pemecahan masalah.

a. Pertama prinsip no. 32 (Color change), yaitu meletakkan nomor antrian didepan pintu masuk sehingga terlihat langsung saat pelanggan memasuki ruangan dan nomor antrian diletakkan pada meja dengan ketinggian yang sesuai dengan tinggi mata pada antopometri masyarakat Indonesia yaitu ketinggian $1325 \mathrm{~mm}$

b. Kedua dengan menerapkan prinsip no. 23 (feedback) yaitu dengan memberikan arahan kepada para staf agar saat memanggil pelanggan berikutnya berdasarkan nomor antrian 
dan minta kembali kertas nomor antrian yang diambil pelanggan.

2. Produk yang Dikirimkan Bebas dari Kerusakan

Kerusakan yang terjadi seperti penyok, pecah, dan sobek karena cairan dan makanan yang tumpah. Hal ini dapat dipecahkan dengan menggunakan 2 prinsip TRIZ, yaitu:

a. Prinsip no. 1 (segmentation) yaitu memisahkan dan mengklasifikasikan barang-barang yang akan dikirim menjadi beberapa kategori sesuai dengan jenis barang.

b. Prinsip no. 9 (preliminary anti action), karena prosedur pemeriksaan barang tidak dapat selalu dilakukan, maka selalu informasikan kepada pelanggan untuk memberitahukan secara jujur isi barang yang akan dikirim agar dapat penanganan khusus.

3. Papan Informasi dan Isinya

Papan informasi terlalu kecil dan terletak di tempat yang kurang terlihat dengan isi yang kurang menarik karena hanya berisi katakata. Dari keempat prinsip yang terdeteksi, hanya prinsip no. 35 yang dipilih sebagai acuan pemecahan masalah.

Prinsip no. 35 (parameter change), yaitu dengan mengubah bahan lembaran informasi dari kertas HVS putih menjadi kertas dengan kualitas dan ketebalan yang bagus sehingga lebih awet dan tidak mudah rusak. Menggunakan warna cerah seperti warna biru untuk background dan warna hitam untuk tulisan pada papan informasi.

4. Kecepatan dalam Melayani Pelanggan

Keluhan dari pelanggan yaitu karena pelayanan yang cukup lama. Dari 3 prinsip tersebut hanya ada 2 prinsip yang digunakan sebagai acuan pemecahan masalah:

a. Pertama dengan menerapkan prinsip no. 29 (pneumatic or hydraulic construction) untuk mempercepat pelayanan berikan pelatihan secara berkala kepada para staf.

b. Kedua dengan menerapkan prinsip no. 34 (discarding and recovering) yaitu mengganti staf yang kinerjanya sudah menurun dengan staf baru yang memiliki kinerja yang lebih baik.

5. Menangani keluhan pelanggan dengan baik Pelanggan yang merasa tidak puas karena pelayanan yang diberikan akan menyampaikan keluhannya. Staf yang tidak merespon keluhan pelanggan menyebabkan rasa ketidakpuasan dari pelanggan bertambah. Hal ini dapat dipecahkan dengan menggunakan 2 prinsip TRIZ, yaitu:

a. Prinsip no. 8 (anti weight) yaitu mendengarkan keluhan pelanggan dengan baik dan sabar, mencatat keluhan yang diberikan, segera perbaiki hal yang dikeluhkan pelanggan dan menjalin komunikasi dengan meminta nomor telepon pelanggan yang memberikan keluhan agar dapat meninjau apakah pelanggan sudah puas setelah keluhannya diperbaiki.

b. Prinsip no. 23 (feedback) yaitu dengan memberikan reward dan punishment yaitu memberikan penghargaan kepada staf yang memberikan kualitas pelayanan terbaik dan memberikan hukuman untuk staf yang memberikan pelayanan secara buruk.

\section{KESIMPULAN}

Melalui Importance Performance Analysis terdapat 7 atribut yang dianggap penting oleh pelanggan adalah menangani keluhan pelanggan dengan baik, kecepatan dalam melayani pelanggan, produk yang dikirimkan bebas dari kerusakan, garansi dari produk yang dikirimkan berdasarkan packaging yang digunakan, tanggung jawab perusahaan atas kehilangan barang yang dikirim, menangani keluhan pelanggan dengan baik dan garansi dari produk yang dikirimkan berdasarkan packaging yang digunakan. Perbaikan dilakukan pada 5 atribut, dimana 3 atribut memiliki nilai gap terbesar yang berada di kuadran prioritas tinggi dan 2 atribut memiliki nilai gap terbesar yang berada di kuadran prioritas rendah. Kelima atribut tersebut yaitu nomor antrian, produk yang dikirimkan bebas dari kerusakan, papan informasi dan isinya, kecepatan dalam melayani pelanggan dan menangani keluhan pelanggan 
dengan baik. Perbaikan atribut dengan menggunakan metode TRIZ adalah: meletakkan nomor antrian di depan pintu masuk dan pada meja dengan ketinggian 1325 mm, memisahkan dan mengklasifikasikan barang-barang yang akan dikirim, mengganti kertas papan informasi menjadi kertas dengan kualitas yang bagus sehingga lebih awet, memberikan pelatihan secara berkala kepada para staf, dan memberikan reward dan punishment kepada karyawan.

\section{DAFTAR PUSTAKA}

[1]. Wijaya, Tony, 2011, Manajemen Kualitas Jasa, Indeks, Jakarta.

[2]. Gaspersz, Vincent, 2001, Total Quality Management, Gramedia, Jakarta.

[3]. Yuliarmi, Ni Nyoman Dan Riyasa, Putu, 2007, Analisa Faktor-Faktor yang Mempengaruhi Kepuasan Pelanggan Terhadap Pelayanan PDAM Kota Denpasar. Jurnal Buletin Studi Ekonomi, Vol.12. No. 1: 9-28.

[4]. Hapsari, Yan, 2008, Analisis Yang Mempengaruhi Kepuasan Pelanggan, Thesis, Universitas Diponegoro.
[5]. Sari, Diana Puspita dan Harmawan, Andry, 2012, Usulan Perbaikan Kualitas Pelayanan Pada Instalasi Rawat Jalan Dengan Metode SERVQUAL Dan Triz (Studi Kasus Di RS. Muhammadiyah Roemani). Jurnal J@TI Undip. Vol.VII. No. 2: 95-104.

[6]. Widiawan, Kriswanto dan Irianty, 2004, Pemetaan Preferensi Konsumen Supermarket dengan Metode Kano Berdasarkan Dimensi SERVQUAL. Jurn. Teknik Industri. Vol.6. No.1: 37-46.

[7]. Mazur, Glenn., TRIZ.USA. http://www.mazur.net/triz/ (diakses pada 3 November 2013)

[8]. Sevilla, Consuelo G. et. Al, 2007. Research Methods. Rex Printing Company. Quezon City.

[9]. Sugiarto. Dergibson, S. Lasmono, T. S dan Deny, S. Oetomo, 2003. Teknik Sampling.

Cetakan Kedua PT Gramedia Pustaka Utama. Jakarta. 